\title{
PHÃ̃U THUẬT NộI SOI TOÀN BỘ KHÔNG ROBOT HỖ TRỌ̉ VÁ THÔNG LIÊN THẤT Ở BỆNH NHÂN NŨ๋ 8 TUỔI
}

Đặng Quang Huy , Phạm Thị Kim Lan*, Trần Đắc Đại , Lê Ngọc Thành ${ }^{*}$, Lê Minh Sơn ${ }^{* *}$

\section{TÓM TẮT}

Thông liên thất (TLT) là bệnh phổ biến, chiếm $30 \%$ các bệnh tim bẩm sinh (TBS), được điều trị chủ yếu bằng phương pháp phẫu thuật tim hở với tuần hoàn ngoài cơ thể. Có rất ít công bố về áp dụng phẫu thuật nội soi toàn bộ (NSTB) có hoặc không có sự hỗ trợ của hệ thống robot trong vá TLT. Trong bài báo này, chúng tôi giới thiệu một trường hợp bé gái 8 tuổi với chẩn đoán TLT quanh màng, còn ống động mạch (ODM) được phẫu thuật thành công bằng phương pháp NSTB không robot hỗ trợ.

Tù khóa: Thông liên thất, phẫu thuật tim nọi soi toàn bộ, phẫu thuật robot

\section{ĐặT VẤN ĐỀ}

Thông liên thất (TLT) là một trong những bệnh TBS phổ biến nhất, chiếm khoảng 30\% tổng số các bệnh TBS.[1] Mặc dù phẫu thuật tim ít xâm lấn (minimally invasive cardiac surgery - MICS) đã phát triển nhanh chóng trong thời gian vừa qua, song ứng dụng của chúng trong điều trị bệnh TLT còn rất hạn chế. Cho đến thời điểm này có rất ít báo cáo về phẫu thuật NSTBtrong điều trị bệnh TLT, đặc biệt ở trẻ nhỏ.[2-4] Trong báo cáo này, chúng tôi công bố trường hợp lâm sàng sử dụng phương pháp NSTB vá TLT ở bé gái 8 tuổi, không có sự hỗ trợ của robot.

\section{TRƯỜNG HỢP BỆNH}

Bệnh nhân (BN) nữ 8 tuổi, nặng $17 \mathrm{~kg}$, phát hiện bệnh TBS từ sau sinh, không theo dõi và điều trị. 1 tháng trước vào viện xuất hiện mệt, khó thở khi chơi đùa cùng các bạn. Khám lâm sàng lúc vào viện có tiếng thổi tâm thu rõ cạnh ức trái, siêu âm tim qua thành ngực cho thấy một lỗ TLT quanh màng lan buồng nhận, đường kính $12 \mathrm{~mm}$, shunt T-P, chênh áp qua lỗ thông $20 \mathrm{mmHg}$, còn ODM đk $4 \mathrm{~mm}$. BN được can thiệp bịt dù ODM trước, 3 tuần sau được áp dụng phẫu thuật NSTB không robot hỗ trợ để vá TLT.

Người bệnh được đặt ở tư thế nằm ngửa, hai tay dọc theo thân người, gây mê thông thường với nội khí quản một nòng. Tuần hoàn ngoài cơ thể (THNCT) ngoại vi được thiết lập với ống thông động mạch $(\mathrm{DM})$ đùi được đặt gián tiếp qua đoạn mạch Dacron số 6; trong khi đó ống thông tĩnh mạch chủ (TMC) trên và $\mathrm{TMC}$ dưới được đặt qua tĩnh mạch (TM) cảnh trong và $\mathrm{TM}$ đùi theo phương pháp Seldinger.Khi bắt đầu chạy máy, áp lực đường ĐM tăng dần tới $260 \mathrm{mmHg}$, chúng tôi chuyển thành đặt ống thông ĐM đùi hai bên với đường $Đ M$ phụ đặt trực tiếp sử dụng

\footnotetext{
* Trung tâm tim mạch, Bệnh viện E

** Khoa phẫu thuật tim mạch và lồng ngục, Bệnh viện Việt Tiệp, Hải Phòng

Người chịu trách nhiệm khoa học: GS.TS. Lê Ngọc Thành

Ngày nhận bài: 01/10/2017 - Ngày Cho Phép Đăng: 05/10/2017

Phản Biện Khoa học: GS.TS. Bùi Đúcc Phú PGS.TS. Đặng Ngoc Hùng
} 
cannula $10 \mathrm{~F}$ (bình thường là $16 \mathrm{~F}$ ). Sau khi có thêm đường $Đ M$ phụ, áp lực đường $Đ M$ giảm xuống và ổn định ở mức $180-200 \mathrm{mmHg}$.

Bốn trocar được thiết lập trên ngực phải của $\mathrm{BN}$, bao gồm: 01 trocar $12 \mathrm{~mm}$ tại khoang liên sườn (KLS) 5 đường nách trước cho tay làm việc chính, 01 trocar $5 \mathrm{~mm}$ tại KLS 4 đường nách giữa cho tay làm việc phụ, 01 trocar $5 \mathrm{~mm}$ tại KLS 5 đường nách giữa cho camera và 01 trocar $5 \mathrm{~mm}$ tại KLS 6 đường nách giữa cho đường hút máu về. Sau khi thắt $\mathrm{TMC}$ trên, kim gốc ĐMC được đặt bằng cách chọc qua thành trước ngực phải. Bảo vệ cơ tim bằng dung dịch $\mathrm{HTK}$ xuôi dòng qua gốc ĐMC sau khi ĐMC được cặp lại bằng clamp Chitwood.

Nhĩ phải (NP) được mở song song với rãnh nhĩ thất, vách liên nhĩ nguyên vẹn, chúng tôi mở một lỗ tại vị trí hố bầu dục để đặt đường hút nhĩ trái. Bộc lộ lỗ thông bằng cách khâu treo thành NP lên màng tim. Lỗ TLT quanh màng lan buồng nhận, nhiều tổ chức dây chằng của lá vách và là trước van ba lá (VBL) bám vắt qua lỗ thông. Chúng tôi xẻ mép lá trước và lá vách để bộc lộ rõ lỗ thông. Lỗ TLT được đóng lại bằng miếng vá nhân tạo, khâu vắt kết hợp khâu mũi rời. NP được khâu vắt hai lớp sau khi mép VBL và lỗ thông ở hố bầu dục được đóng lại. Sau khi thả clamp ĐMC, tim đập lại xoang, đuổi khí qua kim gốc ĐMC. Ngừng THNCT và kết thúc cuộc mổ không gặp khó khăn gì. Thời gian chạy máy và thời gian cặp ĐMC lần lượt là 150 và 185 phút. $S A$ trước khi ra viện vách liên thất kín, VBL không hở. BN ra viện sau mổ 8 ngày không còn những triệu chứng trước mổ; không có biến chứng về thần kinh, mạch máu tại thời điểm khám lại sau 3 tháng. Gia đình rất hài lòng về kết quả phẫu thuật.

\section{BÀN LUẬN}

Phẫu thuật NSTB ít được áp dụng trong điều trị các bệnh TBS đặc biệt ở trẻ nhỏ vì 2 lý do: (1) trẻ có cân nặng thấp thường có kích thước ĐM và $\mathrm{TM}$ đùi nhỏ gây khó khăn trong thiết lập THNCT ngoại vi, tăng nguy cơ thiếu máu chi dưới trong và sau mổ và (2) lồng ngực có kích thước nhỏ gây khó khăn cho thao tác nội soi.[3] Để khắc phục nguy cơ thiếu máu chi dưới trong và sau mổ, chúng tôi đặt ống thông ĐM gián tiếp qua đoạn mạch Dacron. Việc sử dụng đường $\mathrm{M}$ phụ bên trái giúp ổn định áp lực đường ĐM. Vì với mục đích giảm áp, chúng tôi chỉ cần sử dụng ống thông ĐM có kích thước nhỏ hơn $6 \mathrm{~F}$ so với chuẩn dựa trên cân nặng của $\mathrm{BN}$, việc này giúp loại trừ nguy cơ thiếu máu chân trái trong và sau mổ.

Ma cùng cộng sự sử dụng 3 cổng trocar có kích thước lớn $(1-1.5 \mathrm{~cm})$; trong đó, vị trí các cổng trocar nằm về phía trước lồng ngực nhiều hơn. Thời gian chạy máy và thời gian cặp ĐMC của tác giả này ngắn do dụng cụ phẫu thuật tiếp cận rất gần với tổn thương.[2,3] Chúng tôi sử dụng các lỗ trocar nhỏ $(5-12 \mathrm{~mm})$ nằm nhiều về phía đường nách giữa hơn; cách thiết lập trocar này tương tự phương pháp NSTB có robot hỗ trợ của Gao cùng cộng sự.[4] Với kinh nghiệm hơn 85 trường hợp phẫu thuật NSTB sửa thông liên nhĩ, thông sàn nhĩ thất bán phần, cắt màng ngăn nhĩ trái, cắt u nhầy nhĩ trái, chúng tôi áp dụng NSTB trong vá TLT. Thời gian chạy 
máy và thời gian cặp ĐMC của chúng tôi còn dài do chưa có nhiều kinh nghiệm vá TLT qua các lỗ trocar.

Bằng cách khâu treo và xẻ mép lá trước và lá vách của VBL, lỗ TLT quanh màng được bộc lộ khá tốt. Mặc dù lỗ thông lớn và có nhiều dây chằng chạy ngang qua mặt trước, việc vá lỗ thông không gặp nhiều khó khăn. Tuy vậy, chúng tôi thấy phẫu thuật sẽ trở nên khó khăn rất nhiều nếu lỗ TLT lan nhiều về phía van ĐMC. Do đó phẫu thuật NSTB nên được áp dụng cho những BN TLT được lựa chọn kỹ.

\section{TÀI LIỆU THAM KHẢO}

1. Vaidyanathan B, Roth SJ, Rao SG, et al. Outcome of ventricular septal defect repair in a developing country. The Journal of pediatrics. 2002;140(6):736-741.
2. Ma ZS, Wang JT, Dong MF, et al. Thoracoscopic closure of ventricular septal defect in young children: technical challenges and solutions. European journal of cardiothoracic surgery : official journal of the European Association for Cardio-thoracic Surgery. 2012;42(6):976-979.

3. Ma ZS, Yang CY, Dong MF, et al. Totally thoracoscopic closure of ventricular septal defect without a robotically assisted surgical system: a summary of 119 cases. The Journal of thoracic and cardiovascular surgery. 2014;147(3):863-867.

4. Gao C, Yang M, Wang G, et al. Totally endoscopic robotic ventricular septal defect repair in the adult. The Journal of thoracic and cardiovascular surgery. 2012;144(6):1404-1407.

\section{Hình và chú thích hình:}

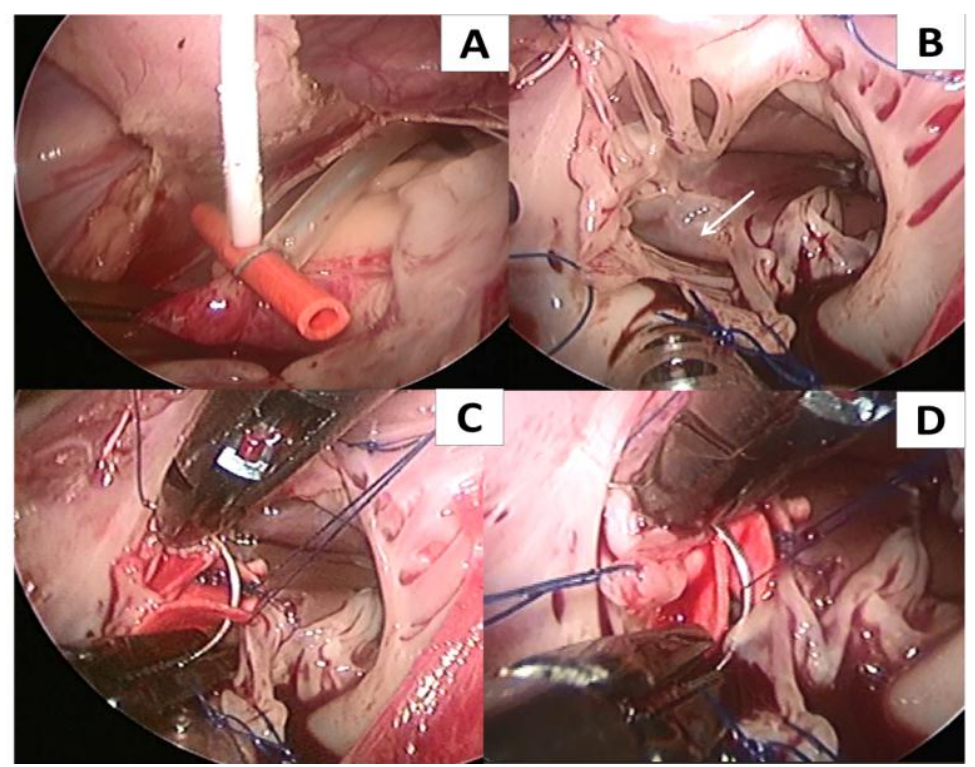

Hình 1, (A): cặp ĐMC bằng clamp Chitwood, liệt tim xuôi dòng bằng dung dịch Custodiol HTK qua gốc ĐMC với kim gốc ĐMC chọc qua thành ngực; (B): Lố TLT quanh màng lan về phía buồng nhận (mũi tên mầu trắng), nhiều dây chằng che mặt truớc mép trên và mép duơoi lỗ thông; (C, D): Vá lỗ TLT sủ dụng miếng vá nhân tạo, khâu vắt kết hợp mũi rời. 